\title{
Influência das condições climáticas sobre a eficácia de fungicidas empregados para o controle do míldio em Vitis vinifera
}

\author{
Effect of environmental conditions on efficacy of fungicides to downy mildew control inVitis vinifera
}

\author{
Ana Beatriz Costa Czermainski ${ }^{1}$ Olavo Roberto Sônego ${ }^{1}$
}

\section{RESUMO}

\begin{abstract}
Um dos fatores a serem manejados para a máxima produtividade de um vinhedo é o míldio, doença causada por Plasmopara viticola, que afeta regiões produtoras de uva do mundo inteiro. No Brasil, são necessárias diversas aplicações de fungicida para seu controle. Diferentes princípios ativos são encontrados no mercado. Com base em resultados de ensaios de fungicidas para controle do míldio em Vitis vinifera conduzidos em 1995 e 1996, foi analisada a influência dos fatores climáticos temperatura do ar, precipitação e umidade relativa do ar sobre a eficácia dos produtos disponíveis. Os experimentos foram instalados na Embrapa Uva e Vinho, sobre a cv. Tannat, conduzida no sistema espaldeira. A análise dos fatores ambientais apontou períodos de infecções primárias e secundárias. A maior ocorrência de chuvas e alta umidade relativa do ar foram determinantes da maior severidade do míldio no ano de 1996. A análise da incidência e do índice de intensidade de doença em folhas e em cachos, indicou maior eficácia dos fungicidas cymoxanil + mancozeb, metalaxil + mancozeb e dithianona, nos dois anos. Os princípios ativos cúpricos - oxicloreto de cobre, isolado ou combinado com mancozeb, e sulfato de cobre - não foram eficazes para controlar o míldio nos cachos sob condições climáticas favoráveis à doença.
\end{abstract}

Palavras-chave: Vitis vinifera, Plasmopara viticola, controle químico, míldio da videira.

\section{ABSTRACT}

One of the factors to be managed for maximum vineyard productivity is the downy mildew, disease caused by Plasmopara viticola that affects grape production in many parts of the world. In Brazil, several fungicide applications for its control are necessary. Different active ingredients are available on the market. The influence of climatic factors (air temperature, rainfall and relative humidity) on fungicide efficacy in Vitis vinifera was analyzed using results of fungicide trials for downy mildew control as a base. The experiments were carried out at Embrapa Uva e Vinho with the cv. Tannat conducted on vertical trellis system during 1995 and 1996. The assessment of the environmental factors pointed out primary and secondary infection periods, being the rainfall and high relative humidity responsible for the high severity in the year 1996. The analysis of the incidence and of the disease rate on leaves and bunches, indicated that the most efficient treatments were cymoxanyl + mancozeb, metalaxyl + mancozeb and dithianon, in the two years. The active ingredients copper oxychloride, alone or combined with mancozeb, and copper sulphate were not efficient for downy mildew control on bunches under favorable environmental conditions to this disease.

Key words: Vitis vinifera, Plasmopara viticola, chemical control, grape downy mildew.

\section{INTRODUÇÃO}

Muitos são os fatores a serem efetivamente manejados para se obter a máxima produtividade de um vinhedo. Um desses fatores é o controle do míldio, doença causada por Plasmopara viticola (Berk. \& Curt) BERL. \& DE TONI, responsável pelos maiores danos para a viticultura no sul do Brasil assim como em outras regiões vitícolas do mundo. Essa doença é especialmente séria em anos com elevada precipitação, alta umidade relativa e longos períodos de umidade sobre folhas e frutos, com perdas que podem atingir $100 \%$ da produção de um vinhedo, como citado por MADDEN et al. (2000), que se refere ao míldio como uma das maiores restrições à produção de uvas em Ohio, EUA.

Esforços têm sido feitos para desenvolver modelos epidemiológicos para $\boldsymbol{P}$. viticola e sistemas de aviso anti-míldio na cultura da videira, mas a relação

${ }^{1}$ Engenheiro Agrônomo, Mestre, Embrapa Uva e Vinho, CP 130, 95700-000, Bento Gonçalves, RS. E-mail: ana@cnpuv.embrapa.br. 
precisa entre fatores ambientais e o ciclo epidemiológico depende da espécie de videira estudada (MADDEN et al., 2000). O desenvolvimento e a validação de modelos resultaram em informações sobre as condições ambientais ótimas de cada fase do ciclo epidemiológico.

TRAN MANH SUNG et al. (1990) mostraram que a dinâmica da maturação de oosporos, a estrutura de resistência de inverno que leva à infecção primária, é variável entre anos e fortemente influenciada pela precipitação pluviométrica. Esses autores concluíram que a quantidade e distribuição das chuvas no período de outono e inverno, para a região de Bordeaux, França, é determinante das fases de maturação e de pósmaturação ou germinação dos oosporos e da severidade da doença na primavera. Eles determinaram, para um período de onze anos, a data ótima de maturação de oosporos (DOM) e observaram alta severidade da doença quando a DOM ocorreu em março, cuja temperatura média foi menor que $10{ }^{\circ} \mathrm{C}$. Para a fase de germinação, os autores citam como essenciais a ocorrência de água livre e de temperatura acima de $11^{\circ} \mathrm{C}$.

LALANCETTE et al. (1987), estudando os processos de infecções secundárias, estabeleceram relações entre ambiente e concentração de esporângios com a produção de zoosporos e severidade de doença. Esses autores publicaram modelos que permitem descrever quantitativamente a eficiência de infecção (número de lesões/zoosporo) como função da temperatura e duração do molhamento foliar (LALANCETTE et al., 1988a) e o processo de esporulação (LALANCETTE et al., 1988b). É ressaltada a dependência da esporulação de $\boldsymbol{P}$. viticola a três fatores ambientais: luz, umidade relativa (UR) e temperatura do ar. A luz tem efeito inibitório havendo necessidade da alternância de luz e escuro para a esporulação. O processo desenvolve-se exclusivamente no período noturno e é facilitado pela alta UR que freqüentemente ocorre durante esse período. A temperatura não foi considerada limitante devido a sua ampla faixa não restritiva $\left(5 \mathrm{a} 25^{\circ} \mathrm{C}\right)$ em que ocorre a esporulação e da qual surgem as infecções secundárias. Os mesmos fatores abióticos que proporcionam a esporulação irão determinar o período de maturação dos esporos, a sua diferenciação para zoosporos e a taxa de germinação dessas unidades infectivas. A duração do período de molhamento foliar permite que a infecção se instale, enquanto a temperatura determina a rapidez e a extensão da infecção. A infecção pode ocorrer entre 5 e $30^{\circ} \mathrm{C}$, uma faixa de temperatura ainda mais ampla do que a faixa de ocorrência da esporulação (LALANCETTE et al., 1988a).

Na maioria das áreas geográficas atingidas, o manejo do míldio requer o uso de fungicidas aplicados diversas vezes durante o período de crescimento das brotações, podendo começar tão cedo como no estádio 17 de Eichhorn-Lorenz - inflorescência desenvolvida, flores separadas (MADDEN et al., 2000). Em ensaio com a cultivar Isabel, SONEGO \& CZERMAINSKI (1999) relataram que, devido às condições climáticas do ano de 1996, a aplicação de fungicidas foi efetuada já no E12 (5 a 6 folhas separadas, inflorescência visível).

O manejo do míldio nas áreas vitícolas da região do sul do Brasil é dependente do uso de fungicidas. A diversidade de princípios ativos registrados no país e eficazes no controle do míldio em $\boldsymbol{V}$. vinifera, possibilita ao produtor escolher o tratamento mais conveniente para o seu vinhedo conforme a disponibilidade no comércio e o retorno econômico. No Brasil, o setor vitícola não conta com sistemas que envolvam atributos climáticos, havendo necessidade de validação para as regiões produtoras.

O objetivo deste trabalho foi avaliar a influência dos fatores climáticos sobre o manejo do míldio em condições de campo, via controle químico, em Vitis vinifera. Foram empregados princípios ativos registrados no Brasil para o controle da doença, utilizando-se a cv. Tannat, considerada bastante suscetível ao míldio da videira.

\section{MATERIAL E MÉTODOS}

Foram utilizados dados de experimentos de controle químico do míldio sobre a cultivar Tannat, conduzidos nas safras de 1995 e 1996, no delineamento de blocos ao acaso com quatro blocos e parcelas de 12 plantas (três fileiras de quatro plantas). O vinhedo estava conduzido no sistema espaldeira, em espaçamento de $2,5 \mathrm{~m}$ entre fileiras e $1,5 \mathrm{~m}$ entre plantas. Os fungicidas aplicados, as doses dos produtos comerciais e os intervalos de aplicação recomendados por 100 litros constam da tabela 1. Os intervalos de aplicação dos tratamentos nas parcelas obedeceram ao critério da persistência do produto (SONEGO \& CZERMAINSKI, 1999). O início das aplicações foi imediato ao aparecimento dos primeiros sintomas de míldio detectados em qualquer cultivar dos vinhedos da Embrapa Uva e Vinho, em Bento Gonçalves, RS, onde situou-se o experimento. Em 1996, ao serem observados os primeiros sintomas, optou-se pela aplicação de metalaxil + mancozeb em toda a área experimental, com o objetivo de uniformizar a 
Tabela 1 - Princípios ativos, classe toxicológica, modo de ação, intervalo de aplicação recomendado, formulação e doses testadas sobre a cv. Tannat para controle do míldio.

\begin{tabular}{|c|c|c|c|c|c|}
\hline $\begin{array}{c}\text { Tratamentos fungicidas } \\
\text { (formulados em pó molhável) }\end{array}$ & $\begin{array}{l}\text { Classe } \\
\text { toxicológica }\end{array}$ & Modo de ação ${ }^{1}$ & $\begin{array}{l}\text { Intervalo de aplicação } \\
\text { recomendado }\end{array}$ & $\begin{array}{c}\text { Concentração (g } \\
\text { i.a. })^{2}\end{array}$ & Dose $\left(\mathrm{g} \text { p.c. } \mathrm{hl}^{-1}\right)^{3}$ \\
\hline Oxicloreto de cobre & IV & $\mathrm{C}$ & 7 a 10 dias & 35 ou 50 & 275 \\
\hline Sulfato de cobre & IV & $\mathrm{C}$ & 7 a 10 dias & 25 & $1 \%$ \\
\hline Oxiclor. de cobre + mancozeb & III & $\mathrm{C}$ & 7 a 10 dias & $20+20$ & 300 \\
\hline Metalaxil + mancozeb & II & $\mathrm{S}+\mathrm{C}$ & 12 a 14 dias & $8+64$ & 300 \\
\hline Folpet & IV & $\mathrm{C}$ & 7 a 10 dias & 50 & 180 \\
\hline Dithianona & II & $\mathrm{C}$ & 7 a 10 dias & 75 & 125 \\
\hline Mancozeb & III & $\mathrm{C}$ & 7 a 10 dias & 80 & 300 \\
\hline Cymoxanil + mancozeb & III & $\mathrm{P}+\mathrm{C}$ & 7 a 10 dias & $8+64$ & 250 \\
\hline
\end{tabular}

${ }^{1} \mathrm{C}=$ Contato; $\mathrm{P}=$ Penetrante; $\mathrm{S}=$ Sistêmico.

i. a.= gramas do ingrediente ativo.

${ }^{3}$ p.c. $=$ gramas do produto comercial por hectolitro.

severidade da doença nas parcelas e evitar a perda total da produção. As aplicações foram realizadas com pulverizador costal manual, com bico tipo cone, molhando-se a vegetação até o ponto de escorrimento, num volume de 6001.ha ${ }^{-1}$ a 10001.ha ${ }^{-1}$, conforme o necessário para completa cobertura da copa. A testemunha correspondeu à ausência de pulverização das plantas no período experimental.

Durante a primavera, no período de crescimento das bagas e após o início das aplicações dos tratamentos, foram efetuadas quatro amostragens de 100 folhas por parcela segundo escala de doze (12) classes de severidade publicada pela EPPO (1981). Dez dias após a última aplicação dos tratamentos, portanto com as plantas no estádio fenológico 33 - bagas no estádio de grão ervilha na escala de Eichhorn \& Lorenz (EPPO, 1984), foram avaliados 50 cachos por parcela, de acordo com uma escala de 0 (sem infecção) a 5 (mais de $50 \%$ de bagas infectadas). Para cada parcela, foi obtida a incidência $(\%)$ de míldio nas amostras de folhas $(\mathrm{n}=100)$ e cachos ( $n=50)$ (IN_fo e IN_ca) e os correspondentes índices de intensidade de doença (ID_fo e ID_ca), calculados com base na transformação angular (CZERMAINSKI, 1999). Os resultados da última amostra de folhas e da avaliação dos cachos foram submetidos à análise de variância multivariada, conjunta para o fator ano, conforme o modelo de delineamento adotado.

Foi efetuada a análise descritiva dos dados de chuva diária no período outono-inverno e considerada a distribuição horária da UR acima de $95 \%$ e da temperatura do ar, visando identificar as diferenças entre os dois anos que levaram às infecções primárias, conforme TRAN MANH SUNG et al. (1990). Para análise dos fatores abióticos sobre o manejo da doença na primavera são apresentados graficamente os dados dos elementos climáticos precipitação, temperatura e dias com UR acima de $95 \%$, no período de 15 de setembro a 15 de dezembro de 1995 e de 1996.

Após o período experimental, com as variáveisresposta já levantadas, seguiram-se três aplicações de calda bordalesa em todas as parcelas, inclusive na testemunha, como é o procedimento usual para a cultura. Por ocasião da colheita, foram registrados o peso e o número de cachos da parcela de modo a subsidiar uma avaliação econômica. A partir de uma orçamentação das despesas decorrentes do uso dos fungicidas (custo do tratamento + custo de aplicação) e do valor da produção, estimou-se o valor da receita adicional obtida com o uso de cada tratamento em relação à testemunha conforme adotado por SONEGO \& CZERMAINSKI (1999), em estudo similar com a mesma doença para a cultivar Isabel. Foi calculado o índice de doença para folhas e cachos de acordo com CZERMAINSKI (1999), os dados submetidos àanalise da variância, e as médias comparadas pelo teste de Tukey.

\section{RESULTADOS E DISCUSSÃO}

No presente trabalho, tomando-se por base o estudo de TRAN MANH SUNG et al. (1990), verificou-se que os elementos climáticos avaliados em 1995 e 1996, durante o período de março a setembro, que caracteriza o outono e inverno na região do sul do Brasil, não apontaram restrições à maturação dos oosporos de P. viticola. Para a germinação dos oosporos, observou-se diferença nos meses de agosto dos dois anos. Em agosto de 1995, não houve coincidência de dias com chuva ou UR alta (acima de $95 \%$ ) com temperatura acima de $11^{\circ} \mathrm{C}$. No entanto, essa condição ocorreu em sete dias do mês de agosto de 1996 (dados não apresentados). Observações da fenologia da cv. Tannat ao longo de dez anos em banco 
ativo de germoplasma de uva da Embrapa Uva e Vinho (dados não publicados) indicam que o início de brotação ocorre em torno de 25 de agosto. Assim, note-se que, uma vez que os oosporos germinem em agosto, já há substrato (brotos e folhas novas) para as infecções primárias. São apresentados na tabela 2 os resultados de IN_fo e ID_fo obtidos durante o período de primavera, para os tratamentos mais eficazes e a testemunha. Embora em datas não coincidentes, pode se observar que em 1996, níveis mais altos da epidemia foram constatados mais cedo que em 1995. Em 10/11/95, a incidência de folhas com sintoma, amostradas nas parcelas da testemunha, foi de $42,3 \%$. Na data mais próxima do ano seguinte (07/ $11 / 96)$, quase a totalidade $(96,3 \%)$ das folhas amostradas nas mesmas parcelas apresentou sintoma.

$\mathrm{O}$ índice de doença verificado na última amostragem de folhas, ID_fo, teve correlação parcial positiva significativa com a percentagem de folhas infectadas, IN_fo $(\mathrm{r}=0,82, \mathrm{P}<0,001)$. O mesmo ocorreu em se tratando dos cachos $(\mathrm{r}=0,78, \mathrm{P}<0,001)$. Nenhuma outra correlação significativa foi observada entre as variáveis. Assim, foi efetuada a análise de variância multivariada para ID_fo e ID_ca, que indicou alta significância dos efeitos principais (tratamento e ano, Lambda de Wilks iguais a 0,001 e 0,06 , respectivamente, $\mathrm{P}<0,001$ ) e da interação entre eles (Lambda de Wilks=0,07, P<0,001). A análise por ano, confirmou o efeito altamente significativo dos tratamentos (Lambda de Wilks < 0,02 nos dois anos, $\mathrm{P}<0,001)$. O ID_fo entre os tratamentos com fungicidas, atingiu o máximo de $10,3 \%$ em 1995 e $15,9 \%$ em 1996. Na testemunha, esse índice ficou acima de $80 \%$ nos dois anos, com o IN_fo atingindo $100 \%$ em 1996 (Tabela 3). Os produtos mais eficazes no controle da doença foram cymoxanil +

Tabela 2 - Incidência e índice de intensidade de míldio (IN_fo e ID_fo) em amostras de 100 folhas por parcela, na primavera de 1995 e 1996, nas parcelas da testemunha e nos tratamentos de maior eficácia de controle da doença.

\begin{tabular}{|c|c|c|c|c|c|c|c|c|c|}
\hline \multirow{3}{*}{$\begin{array}{l}\text { Condição } \\
\text { Experimental }\end{array}$} & \multirow{3}{*}{ Média (\%) } & \multicolumn{4}{|c|}{ Datas das amostragens } & & & & \\
\hline & & \multicolumn{4}{|c|}{1995} & \multicolumn{4}{|c|}{1996} \\
\hline & & $10 /$ nov & $17 /$ nov & 29/nov & $11 / \mathrm{dez}$ & $11 /$ out & 28/out & 07/nov & $20 /$ nov \\
\hline \multirow{2}{*}{$\begin{array}{l}\text { Metalaxil + } \\
\text { mancozeb }\end{array}$} & IN_fo & 0,5 & 0,25 & 2,25 & 6,5 & 0,25 & 1 & 3,75 & 25 \\
\hline & ID_fo & 0,005 & 0,002 & 0,13 & 0,53 & 0,002 & 0,04 & 0,15 & 6,71 \\
\hline \multirow{2}{*}{ Dithianona } & IN_fo & 0,75 & 0,75 & 1,5 & 8,75 & 0,25 & 6,25 & 9 & 22 \\
\hline & ID_fo & 0,01 & 0,02 & 0,07 & 0,59 & 0,002 & 0,53 & 0,62 & 2,61 \\
\hline \multirow{2}{*}{$\begin{array}{l}\text { Cymoxanil + } \\
\text { mancozeb }\end{array}$} & IN_fo & 0 & 0,25 & 1,25 & 3,75 & 0,78 & 1 & 2,25 & 4,5 \\
\hline & ID_fo & 0 & 0,002 & 0,04 & 0,28 & 0,01 & 0,02 & 0,07 & 0,38 \\
\hline \multirow{2}{*}{ Testemunha } & IN_fo & 42,3 & 47 & 85,5 & 99 & 2,75 & 58,9 & 96,3 & 100 \\
\hline & ID_fo & 6,8 & 9,2 & 40,3 & 80,7 & 0,1 & 13,5 & 68,1 & 95,2 \\
\hline
\end{tabular}

Tabela 3 - Incidência de folhas (IN_fo) e de cachos (IN_ca) com sintomas de míldio e índice de intensidade de doença nas folhas (ID_fo) e nos cachos (ID_ca), expressos em porcentagem, em dois anos de avaliação de fungicidas sobre a cv. Tannat.

\begin{tabular}{|c|c|c|c|c|c|c|c|c|}
\hline \multirow{4}{*}{ Tratamentos } & \multicolumn{4}{|c|}{ Avaliação de folhas } & \multicolumn{4}{|c|}{ Avaliação de cachos } \\
\hline & \multicolumn{4}{|c|}{ Ano } & \multicolumn{4}{|c|}{ Ano } \\
\hline & \multicolumn{2}{|c|}{1995} & \multicolumn{2}{|c|}{1996} & \multicolumn{2}{|c|}{1995} & \multicolumn{2}{|c|}{1996} \\
\hline & IN_fo & ID_fo & IN_fo & ID_fo & IN_ca & ID_ca & IN_ca & ID_ca \\
\hline Oxicloreto de cobre & 45,8 & 10,3 & 77,5 & 15,9 & 24,5 & 13,8 & 95,0 & 90,6 \\
\hline Sulfato de cobre & 15,0 & 1,9 & 57,3 & 12,7 & 22,5 & 6,7 & 84,0 & 69,2 \\
\hline Oxicloreto cobre + mancozeb & 17,8 & 1,9 & 28,8 & 4,5 & 6,0 & 0,8 & 56,0 & 38,6 \\
\hline Metalaxil + mancozeb & 6,5 & 0,5 & 25,0 & 6,7 & 3,0 & 0,3 & 30,5 & 16,9 \\
\hline Folpet & 22,8 & 3,4 & 59,3 & 14,6 & 12,0 & 2,4 & 37,0 & 19,1 \\
\hline Dithianona & 8,8 & 0,6 & 22,0 & 2,6 & 3,0 & 0,3 & 14,5 & 4,6 \\
\hline Mancozeb & 18,3 & 2,0 & 51,0 & 10,1 & 6,5 & 0,8 & 37,5 & 16,9 \\
\hline Cymoxanil + mancozeb & 3,8 & 0,3 & 4,5 & 0,4 & 5,0 & 0,4 & 8,5 & 1,2 \\
\hline Testemunha & 99,0 & 80,7 & 100 & 95,2 & 96,5 & 83,0 & 100 & 100 \\
\hline
\end{tabular}


mancozeb, metalaxil + mancozeb e dithianona, com ID_fo abaixo de $7 \%$ e ID_ca abaixo de $17 \%$, nos dois anos de ensaio. A testemunha teve ID_ca de $83 \%$ em 1995 com $96,5 \%$ de incidência, e de 100\% em 1996 com $100 \%$ das unidades atacadas (Tabela 3). Em 1995, nas parcelas com controle químico, o índice máximo de doença atingido foi de 10,3 nas folhas e de 13,8 nos cachos, enquanto que em 1996 foram, respectivamente, de 15,9 e 90,6. Constatou-se, portanto, que em 1995, todos os fungicidas foram eficazes no controle do míldio tanto nas folhas quanto nos cachos, enquanto em 1996, os princípios ativos cúpricos - oxicloreto de cobre, isolado ou combinado com mancozeb, e sulfato de cobre - não foram eficazes para controlar o míldio nos cachos. Essas diferenças ressaltam a importância da análise das condições ambientais em cada ano de cultivo.

O comportamento dos elementos climáticos bem como os primeiros sintomas de míldio na área experimental foram observados em 24/10/95 (estádio 23) e 07/10/96 (estádio 12), nas safras 1995/96 e 1996/ 97 respectivamente.

As datas das aplicações dos tratamentos e do aparecimento dos primeiros sintomas nas plantas da área experimental, com os correspondentes estádios fenológicos nos anos de 1995 e 1996, são mostrados, respectivamente, nas figuras 1 e 2 . Pode se observar a medida diária da temperatura (mínima, média e máxima) e da precipitação e dias com UR acima de $95 \%$, no período de 15 de setembro a 15 de dezembro, quando, provavelmente, estariam ocorrendo os ciclos sucessivos de infecção. Embora tenha sido estabelecido o critério para o início e intervalos de aplicações, a cada ano observaram-se peculiaridades que levaram a mudanças no procedimento experimental como relatado a seguir.

Em 1995, entre 23 de setembro a 05 de outubro ocorreu chuva ou alta UR e a temperatura oscilou entre 9,4 e $24,7^{\circ} \mathrm{C}$, com média de $16,2^{\circ} \mathrm{C}$. Essas condições estão de acordo com as descritas por LALANCETTE et al. (1988a; 1988b) para a produção de zoosporos. Os primeiros sintomas de doença foram observados nas folhas em 20/10/95 (Figura 1), sendo em seguida efetuada, nas respectivas parcelas, a primeira aplicação dos tratamentos (A1) e sete dias após, em virtude da ocorrência de chuva, foi efetuada a segunda aplicação (A2), ainda que o tratamento metalaxil + mancozeb fosse desnecessário nesse momento. A partir daí, as condições climáticas possibilitaram intervalos de 15 dias entre aplicações resultando em apenas três aplicações do metalaxil+mancozeb e quatro dos demais tratamentos (Figura 1). A percentagem de folhas e de cachos atacados foi mais baixa que em 1996, indicando menor disseminação do patógeno (Tabela 3). A baixa precipitação e baixa UR nesse ano evitaram o avanço da epidemia, limitando os ciclos pela indisponibilidade de água livre.

Na figura 2, referente ao ano de 1996, observa-se a ocorrência de alta precipitação

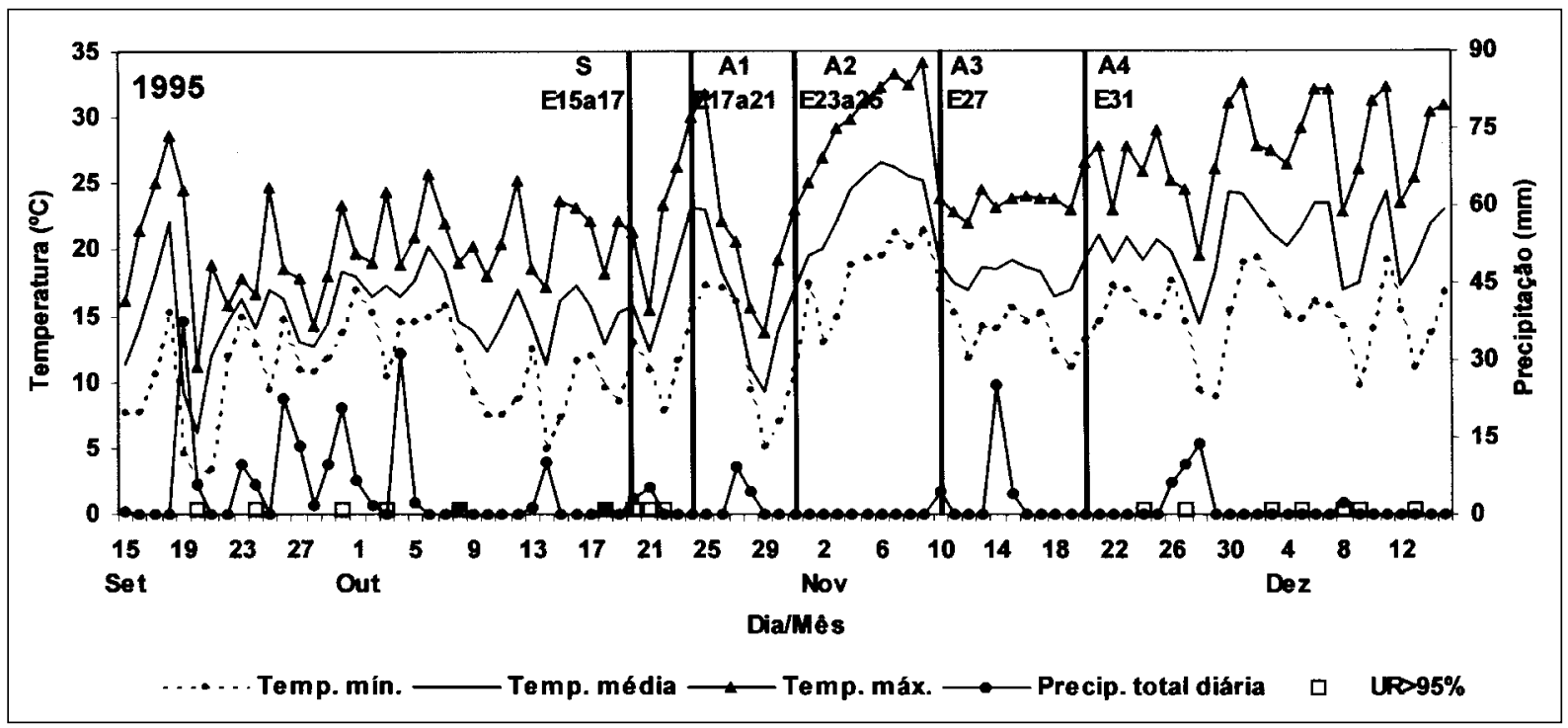

Figura 1 - Temperaturas diárias, precipitação pluviométrica diária e dias com UR acima de 95\% observadas no período de 15/09 a 15/12/95. Datas de aplicação dos tratamentos (A) nas respectivas parcelas e do aparecimento dos primeiros sintomas (S), com os estádios fenológicos (E) correspondentes. A1, A2 e A4 = aplicação de todos os tratamentos; A3= aplicação de todos os tratamentos, exceto metalaxil+ mancozeb. 


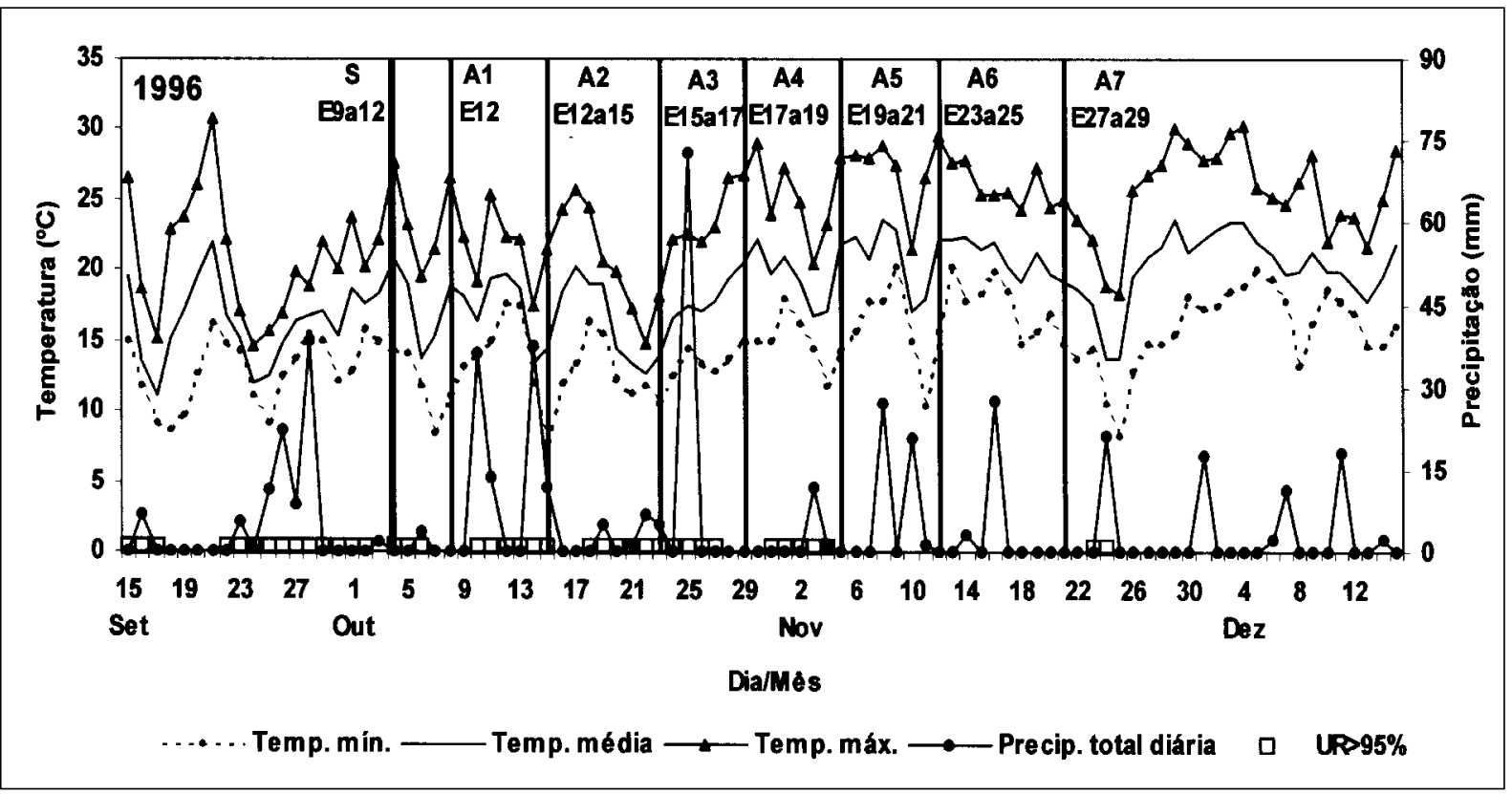

Figura 2 - Temperaturas diárias, precipitação pluviométrica diária e dias com UR acima de 95\% observadas no período de 15/09 a 15/12/96. Datas de aplicação dos tratamentos (A) e do aparecimento dos primeiros sintomas (S), com os estádios fenológicos (E) correspondentes. A1 = metalaxil + mancozeb em todas as parcelas; A2, A4, A6 e A7 = aplicação de todos os tratamentos nas respectivas parcelas; A3 e A5 = aplicação dos tratamentos exceto metalaxil + mancozeb, nas respectivas parcelas.

pluviométrica e muitos dias de UR acima de $95 \%$. Os primeiros sintomas foram observados mais cedo que no ano anterior, com as plantas ainda no estádio E12. Nos doze dias anteriores, observou-se UR > 95\%, por período mínimo de 3 horas diárias noturnas, atingindo até 19 horas consecutivas, com temperaturas que oscilaram de $9,1^{\circ} \mathrm{C}$ a $27,6^{\circ} \mathrm{C}$ e médias diárias entre $11,9^{\circ} \mathrm{C}$ e $20,7^{\circ} \mathrm{C}$. Essas condições favoreceram tanto a esporulação, que pode ocorrer durante noites consecutivas, como as infecções (LALANCETTE et al., 1988a, 1988b). Após a aplicação de metalaxil + mancozeb em toda a área experimental (A1), com a continuidade das condições favoráveis à doença, o critério para as aplicações dos tratamentos foi seguido, a não ser pela ocorrência de chuvas (Figura 2). Isso acarretou, nas respectivas parcelas, mais quatro aplicações do metalaxil + mancozeb e seis dos demais tratamentos. Os altos índices de doença e de incidência na testemunha, tanto nas folhas como nos cachos, indicaram que as condições climáticas favoreceram o desenvolvimento da epidemia.

A análise econômica, utilizando-se a estimativa de produção dos tratamentos e o número médio de aplicações dos dois anos, mostrou que o maior valor adicional foi obtido com aplicação do tratamento cymoxanil + mancozeb, seguido pelo metalaxil + mancozeb. A dithianona, embora com boa eficácia, proporcionou menor valor adicional que os fungicidas anteriormente citados, devido ao seu maior custo (Tabela 4).

A eficiência do produto no controle químico de doenças de plantas envolve não só baixo custo financeiro mas também o aspecto ambiental. Decisões de manejo devem ser baseadas em dados ambientais e de incidência da doença, de modo a diminuir o número de aplicações e promover a escolha de produtos eficazes e de baixa toxicidade.

\section{CONCLUSÕES}

Os elementos climáticos temperatura, precipitação e UR, no período de crescimento das brotações, influenciaram a eficiência do controle químico do míldio em Vitis vinifera.

Os produtos cymoxanil + mancozeb e metalaxil + mancozeb e dithianona, de classes toxicológicas mais baixas, foram os mais eficazes no controle do míldio na cv. Tannat, independente das condições climáticas observadas em cada ano.

Considerando a média dos dois anos, cymoxanil + mancozeb foi o produto que apresentou o maior retorno econômico.

Os princípios ativos cúpricos oxicloreto de cobre, isolado ou combinado com mancozeb, e o 
Tabela 4 - Análise econômica do controle do míldio da videira cv. Tannat, com aplicação dos principais fungicidas registrados para a doença.

\begin{tabular}{|c|c|c|c|c|c|c|}
\hline Tratamentos & $\begin{array}{l}\mathrm{N}^{\circ} \text { de aplica-ções } \\
\text { anuais }\end{array}$ & $\begin{array}{l}\text { Produção estimada } \\
\qquad\left(\mathrm{Kg} \mathrm{ha}^{-1}\right)\end{array}$ & $\begin{array}{c}\text { Valor da } \\
\text { produção }(\mathrm{VP}) \\
\left(\mathrm{R} \$ \mathrm{ha}^{-1}\right)^{1}\end{array}$ & $\begin{array}{c}\text { Custo do } \\
\text { tratamento }(\mathrm{CT}) \\
\left(\mathrm{R} \$ \mathrm{ha}^{-1}\right)\end{array}$ & $\begin{array}{l}\text { Receita }(V P- \\
\mathrm{CT})\left(\mathrm{R} \$ \mathrm{ha}^{-1}\right)^{2}\end{array}$ & $\begin{array}{c}\text { Receita bruta } \\
\text { adicional }\left(\mathrm{R} \$ \mathrm{ha}^{-1}\right)^{3}\end{array}$ \\
\hline Oxicloreto de cobre & 06 & 12285,26 & 12285,26 & 99,00 & 12186,26 & 8270,58 \\
\hline Sulfato de cobre & 06 & 11893,69 & 11893,69 & 105,60 & 11788,09 & 7872,41 \\
\hline $\begin{array}{l}\text { Oxicloreto cobre+ } \\
\text { mancozeb }\end{array}$ & 06 & 11188,87 & 11188,87 & 225,00 & 10963,87 & 7048,19 \\
\hline Metalaxil + mancozeb & 04 & 14716,32 & 14716,32 & 474,00 & 14242,32 & 10326,64 \\
\hline Folpet & 06 & 11697,08 & 11697,08 & 129,60 & 11567,48 & 7651,80 \\
\hline Dithianona & 06 & 11430,48 & 11430,48 & 555,00 & 10875,48 & 6959,80 \\
\hline Mancozeb & 06 & 13138,38 & 13138,38 & 216,00 & 12922,38 & 9006,70 \\
\hline Cymoxanil+mancozeb & 06 & 14659,67 & 14659,67 & 412,50 & 14247,17 & 10331,49 \\
\hline Testemunha & 00 & 3915,68 & 3915,68 & - & 3915,68 & - \\
\hline
\end{tabular}

${ }^{1}$ Produção estimada $\left(\mathrm{kg} \mathrm{ha}^{-1}\right)$ x R \$ 1,00 (valor médio de comercialização na safra de 2000).

${ }^{2}$ Receita absoluta obtida com os tratamentos.

${ }^{3}$ Receita bruta adicional relativamente à testemunha.

sulfato de cobre, de classes toxicológicas III e IV, apresentaram baixa eficácia no controle do míldio nos cachos, em anos de alta precipitação e alta UR do ar, como ocorreu no ano de 1996.

Em anos de menor precipitação e baixa UR do ar, os fungicidas cúpricos, menos tóxicos, podem ser adotados pelos viticultores.

\section{REFERÊNCIAS BIBLIOGRÁFICAS}

CZERMAINSKI, A.B.C. Generalização de um índice de intensidade de infecção em experimentos de avaliação de doenças em plantas. Pesquisa Agropecuária Brasileira, Brasília, v.34, p.1545-1556, 1999.

EUROPEAN AND MEDITERRANEAN PLANT PROTECTION ORGANIZATION (EPPO). Guideline for the biological evaluation of fungicides. S.1.: Plasmopora viticola, 1981. 5p.

EUROPEAN AND MEDITERRANEAN PLANT PROTECTION ORGANIZATION (EPPO). Crop growth stage keys. OEPP/EPPO Bull, v.142, p.295-298, 1984.

LALANCETTE, N.; ELLIS, M.A.; MADDEN, L.V.
Estimating infection efficiency of Plasmopara viticola on grape. Plant Disease, St. Paul, v.71, p.981-983, 1987.

LALANCETTE, N.; ELLIS, M.A.; MADDEN, L.V. Development of an infection efficiency model for Plasmopara viticola on american grape based on temperature and duration of leaf wetness. Phytopathology, St. Paul, v.78, p.794-800, $1988 \mathrm{a}$.

LALANCETTE, N.; MADDEN, L.V.; ELLiS, M.A. A quantitative model for describing esporulation of Plasmopara viticola on grape leaves. Phytopathology, St. Paul, v.78, p.1316-1321, 1988b.

MADDEN, L.V. et al. Evaluation of a disease warning system for downy mildew of grapes. Plant Disease, St. Paul, v.84, p.549-554, 2000 .

TRAN MANH SUNG, C.; STRIZYK, S.;, CLERJEAU, M. Simulation of the date of maturity of Plasmopara viticola oospores to predict the severity of primary infection in grapevine. Plant Disease, St. Paul, v.74, p.120-124, 1990.

SONEGO, O.R.; CZERMAINSKI, A.B.C. Eficácia de fungicidas para o controle do míldio da videira cv. Isabel. Bento Gonçalves : Embrapa Uva e Vinho, 1999. 16p. (Boletim 